\title{
Nutritional Yield of African Indigenous Vegetables in Water-Deficient and Water-Sufficient Conditions
}

\author{
Jen Wen Luoh1, Caroline B. Begg', Rachael C. Symonds ${ }^{3}$, Dolores Ledesma4, Ray-Yu Yang1 ${ }^{*}$ \\ ${ }^{1}$ Nutrition, AVRDC-The World Vegetable Center, Tainan, Taiwan \\ ${ }^{2}$ Department of Plant Science, McGill University, Ste-Anne-de-Bellevue, Canada \\ ${ }^{3}$ Biotechnology and Molecular Breeding, AVRDC-The World Vegetable Center, Tainan, Taiwan \\ ${ }^{4}$ Biostatistics, AVRDC-The World Vegetable Center, Tainan, Taiwan \\ Email: ray-yu.yang@worldveg.org
}

Received 27 December 2013; revised 27 January 2014; accepted 4 February 2014

Copyright (C) 2014 by authors and Scientific Research Publishing Inc.

This work is licensed under the Creative Commons Attribution International License (CC BY).

http://creativecommons.org/licenses/by/4.0/

(c) (i) Open Access

\begin{abstract}
Water scarcity in certain regions of sub-Saharan Africa impacts agricultural production while prolonging dry seasons, and contributing to food insecurity and malnutrition. The objectives of the study were to evaluate the nutritional yield (edible yield $\times$ nutritional content) of indigenous leafy vegetables commonly consumed in Africa under water-stressed conditions. Two species of amaranth, two species of African nightshade, and two varieties of Ethiopian kale were examined under environment-controlled water-sufficient and water-deficient conditions. Fresh and dry stem and leaf weights significantly decreased in the three crop groups under the water-deficient treatment. Nutritional values for carotenoids, tocopherols, calcium and zinc showed significant differences at the content level among treatments. Among the 6 crops evaluated, the amaranth species named Amaranthus hypochondriacus and the African nightshade species named Solanum scabrum had the lowest nutrient losses in drought conditions.
\end{abstract}

\section{Keywords}

African Vegetables; Abiotic Stress; Drought Tolerant; Micronutrients; Antioxidant Activity

\section{Introduction}

Water scarcity in parts of sub-Saharan Africa is spreading due to a decline in annual rainfall levels and overuse ${ }^{*}$ Corresponding author. 
of renewable water sources [1]. Increased demand for water from growing populations and the effects of climate change intensify the impact of water scarcity experienced in semi-arid and arid regions of Africa [2]. Domestic water usage, however, is only one factor contributing to declining water levels. The production of industrial and agricultural goods traded internationally also consumes water. Inadequate local, regional and national water supplies directly affect the amount of available drinking water and food. Dry seasons are prolonged as a consequence of decreased water quantity in Africa, widening the already existing "hunger gap" that occurs in the dry months. The Intergovernmental Panel on Climate Change (IPCC) predicts that by the end of the century, Africa as a whole will have an increase of $5 \%$ to $8 \%$ in dryland and up to $50 \%$ reduction in agricultural production in some countries [2].

Water scarcity is a major threat to food and nutritional security [3]. Regional declines in water availability result in drought, erosion, soil-nutrient deprivation and high salinity [4]. Ultimately, the soil becomes unproductive and the area of arable land is reduced. Adaptation to water shortage is one of the main focuses of climate change adaptation programs in Africa [4] [5]. The aim of such programs is to reduce water wastage and excessive withdrawals that may cause the current food security situation to deteriorate. Food security amid low water availability could be achieved through sustainable water resource management.

Among various adaptation mechanisms, selection and promotion of nutritious food crops with low water requirements for smallholder farmers and home gardens can improve a community's nutritional and health status. Past and present foreign influences on African cultures have altered traditional diets [6]. However, the usage and cultivation of traditional or indigenous vegetables is still widespread in most African countries [7]-[9]. Indigenous vegetables such as amaranth (Amaranthus sp.), jute mallow (Corchorus olitorius), African nightshade (Solanum scabrum and S. villosum) and Ethiopian kale (Brassica carinata) are commonly consumed by African households [10] [11]. Compared with some widely consumed vegetables such as common cabbage, tomato, and onions, many indigenous vegetables are relatively rich in vitamins, minerals, dietary fiber and protein [12]. Moreover, consumption of leafy indigenous vegetables is more prevalent in poor households as emergency food sources during shortages [9] [13]. Indigenous vegetables are mostly collected from the wild rather than cultivated. Some local leafy vegetables previously studied for susceptibility to drought include African-type amaranth and nightshade [14]-[16].

Few studies have examined the nutritional yield of these indigenous vegetables under water-limited conditions. Nutritional yield (biomass yield $\mathrm{x}$ nutrient content) refers to the amount of nutrient in the edible portion of the total biomass of the vegetable. Low biomass production due to water deficiencies may result in lower nutritional yield, as water is a crucial active transporter of plant nutrients [17]. Plant responses to water-deficit include: decreased leaf area, leaf abscission, root extension, stomata closure and decreased photosynthetic activity [18]. These responses would affect plant nutrition.

Food crops promoted for community climate change adaptation programs should be drought tolerant, and high in nutrient content. The purpose of this study is to assess the nutritional yield of leafy indigenous vegetables in water-deficient and water-sufficient conditions. The experiment was conducted to examine the feasibility of using these vegetables as nutritional alternatives in water scarce regions. It also serves as a pilot study for the cultivation of selected leafy indigenous vegetables by smallholder farmers and household gardens in Africa.

\section{Materials and Methods}

\subsection{Crops}

Three vegetable crops (Amaranth, African nightshade and Ethiopian kale) were chosen due to their similar growth rates, and popularity in production and consumption throughout Africa [19]. Two varieties from each of the three vegetable crops (for a total of six entries) were selected for the study based on their African origin, nutritional content and consumer acceptability: amaranth species Amaranthus cruentus var. AC-NL (named A1 in the study) and Amaranthus hypochondriacus var. AH-TL (A2); Ethiopian kale (Brassica carinata) varieties Mbeya Green (K1) and ST3 (K2), and African nightshade species Solanum scabrum Line BG 16, bitter type (N1) and Solanum villosum var. SV, sweet type (N2) (Table 1). The seeds for the experiment were obtained from AVRDC-The World Vegetable Center's regional office in Arusha, Tanzania.

\subsection{Growing Conditions}

The experiment was conducted in a glasshouse at AVRDC-The World Vegetable Center, located in Shanhua, 
Table 1. Common name and scientific name of six African indigenous vegetable entries.

\begin{tabular}{cccc}
\hline Crop entry & Crop name & Scientific name & Variety \\
\hline A1 & Amaranth & Amaranthus cruentus & AC-NL \\
A2 & Amaranth & Amaranthus hypochondriacus & AH-TL \\
K1 & Ethiopian kale & Brassica carinata & Mbeya Green \\
K2 & Ethiopian kale & Brassica carinata & ST3 \\
N1 & African nightshade & Solanum scabrum & Line BG 16 \\
N2 & African nightshade & Solanum villosum & SV \\
\hline
\end{tabular}

Taiwan (latitude $23^{\circ} 8^{\prime} 3^{\prime \prime} \mathrm{N}$, longitude $120^{\circ} 17^{\prime} 18^{\prime \prime} \mathrm{E}$ ). The glasshouse was controlled at a day photoperiod of $13 \mathrm{~h}$ and maintained at the relative humidity of $75 \%$ with a daytime temperature of $35^{\circ} \mathrm{C}$ and night-time temperature of $25^{\circ} \mathrm{C}$. The plants were grown in a sandy loam potting mixture containing soil: rice husk: sand: organic matter in a ratio of 3:1:1:2.

\subsection{Experimental Design}

Two water treatments, water-sufficient (WS) and water-deficient (WD) were applied to the six vegetable entries. The 12 treatments ( 2 water treatments $\times 6$ entries) were arranged in a randomized complete block design (RCBD) with 4 blocks. Each treatment included three plants with one plant grown per pot. In addition, three plants per entry were grown for observation of days to wilting, days to recovery from wilting with watering, and days to death without watering. These plants were not included in the plant and nutritional measurements.

Seedlings were sown into 70-cell seedling trays $(340 \mathrm{~mm} \times 285 \mathrm{~mm} \times 50 \mathrm{~mm}$ ). Two seeds were planted per cell and thinned to one plant after appearance of the first true leaf. 20 days after sowing, the seedlings at 4-leaf stage were transplanted into plastic pots $(140 \mathrm{~mm} \times 140 \mathrm{~mm})$ with one plant per pot, each containing $3.5 \mathrm{~kg}$ of weighed potting mixture. Soil moisture of each pot was measured daily using a portable soil moisture meter (Fujian E-INGINST Electron Co., Ltd., China) on a scale of 1 to 10 (1 - 3, dry; 4 - 7, appropriate water content; 8 10 , wet).

All the plants were watered to the scale of 8 for the first week after transplanting. Otherwise, plants reached the terminal wilting point approximately 3 days without watering after transplanting. The water treatment started on the $27^{\text {th }}$ day after sowing. The water-sufficient treatments were watered to the scale of 8 once every morning until harvesting day. The water-deficient treatment was watered once when plants showed signs of wilting which was the $37^{\text {th }}$ day after sowing $\left(10^{\text {th }}\right.$ day after treatment). The watering allowed the plants to recover from wilting. The water treatment is illustrated in Table 2.

Amaranth, Ethiopian kale, and nightshade treatments in all blocks were harvested at 40 days, 43 days, and 45 days after sowing, respectively, when plants reached commercial maturity. Plants within plots were bulked at harvest, measured for plant traits of interest, and prepared for analyses of nutritional traits.

\subsection{Plant Measurements}

Leaves, roots and stems were separated from the three plants in each plot. Fresh weight was determined and dry weight was measured after drying in an oven for $48 \mathrm{~h}$ at $85^{\circ} \mathrm{C}$. The weight of the edible portion is a combined weight of tender leaves and young shoots.

\subsection{Sample Preparation for Nutritional Analyses}

The edible portion (tender leaves and young shoots) was weighed and divided in half for oven drying to determine dry matter and mineral contents. The other half was divided into several $20 \mathrm{~g}$ samples for storage at $-70^{\circ} \mathrm{C}$ to measure antioxidant activity (AOA), ascorbate content and for freeze-drying to measure carotenoids and tocopherols content. Nutritional yield was calculated as follows: Nutritional yield (mg.plant ${ }^{-1}$ ) $=$ Nutrient content $\left(\mathrm{mg}(100 \mathrm{~g})^{-1}\right) \times$ Fresh edible yield $\left(\mathrm{g} \cdot\right.$ plant $\left.^{-1}\right)$. 
Table 2. Watering plan for water-sufficient and water deficient treatments.

\begin{tabular}{lccccc}
\hline & Seedling Period & Transplanting & Establishment Period & Water Treatment Period & Harvest \\
\hline Days after sowing & $0-20$ & 21 & $22-27$ & 28-Harvest & 40 day: A1, A2 \\
Water-sufficient & & Water everyday & & Water everyday & 43 day: K1, K2 \\
Water-deficient & Water everyday & Way: N1, N2 & \\
\hline
\end{tabular}

\subsection{Dry Matter and Minerals}

Oven-dried samples were ground into fine powder with cyclone mill (Pulverisette 14701, FRITSCH, Germany). Dry matter was determined from the weight difference of $0.5 \mathrm{~g}$ of fine powder before and after placing in an oven at $135^{\circ} \mathrm{C}$ for four hours. The determination of calcium, iron, and zinc contents was performed by ashing procedure, strong acid washing and then detection with atomic absorption spectroscopy [20].

\subsection{Carotenoids}

The primary carotenoids in leafy vegetables are neoxanthin, (all-E)-violaxanthin, (all-E)-lutein and (all-E)- $\beta$ carotene [21] [22]. Commercial carotenoids were purchased and used for identification and qualifications. Carotene analyses in the laboratory were carried out under red light. Glassware was either brown-colored or protected from light. According to preliminary tests, saponification was not necessary for carotenoid analyses of the three crops. Carotenoid extraction and separation were performed following the procedure of our previous work described in Hanson et al. [23]. Briefly, about $200 \mathrm{mg}$ of freeze dried fine powder was rinsed in $0.8 \mathrm{ml}$ of distilled water followed by $9.2 \mathrm{ml}$ of acetone. The extract was evaporated under a nitrogen air flow and re-dissolved in $2 \mathrm{ml}$ of $1 \%$ tetrahydrofuran (THF) in methanol.

Separation and identification of carotenoids was performed using a HPLC system (Waters 2695, Milford, MA, USA) equipped with an auto-sampler, a photodiode array detector (Waters 996) monitoring 210 - $700 \mathrm{~nm}$, Millennium software, and a $\mathrm{C}_{30}$ Column (YMC ${ }^{\mathrm{TM}}, 3.0 \mu \mathrm{m}, 4.6 \mathrm{~mm} \times 150 \mathrm{~mm}$ ). The running conditions were set at $30^{\circ} \mathrm{C}$ using a gradient at $1.3 \mathrm{ml} / \mathrm{min}$ from $0 \%$ to $1 \%$ THF in methanol at $0-15 \mathrm{~min}, 1 \%$ to $25 \%$ THF in methanol at $15-25 \mathrm{~min}, 25 \%$ to $70 \%$ THF in methanol at $25-50 \mathrm{~min}$, and the final $100 \%$ THF at $50-60 \mathrm{~min}$. Identification of sample carotenoids was performed by comparing retention time and light absorption spectra (350 nm - 700 $\mathrm{nm}$ ) of known standards and co-elution of spiked known standards to samples. The peak areas were calibrated against known amounts of standards. The content of carotenoid standards was measured according to their OD reading and specific extinction coefficient $\left(E_{1 \mathrm{~cm}}^{1 \%}\right)$ in respective solvent.

\subsection{Tocopherols}

Freeze-dried samples were ground into fine powder by cyclone mill. About 200 - $500 \mathrm{mg}$ powder was used for tocopherol analysis. The extraction and saponification procedures were followed as described in Osuna-García et al. [24]. Separation and quantification were performed using high performance liquid chromatography (HPLC Waters, Midford, MA, USA) equipped with a 717 plus autosampler, 600E solvent delivery system, 2487 detector (read at $294 \mathrm{~nm}$ ) and a data management system (Empower software). A $250 \times 2 \mathrm{~mm}$ Phenomenex Prodigy ODS-2 column ( $5 \mathrm{~mm}$ particle size) was used under isocratic conditions at ambient temperatures. The mobile phase was acetonitrile: methanol $(85: 15, \mathrm{v} / \mathrm{v})$ at a flow rate of $0.4 \mathrm{ml} \cdot \mathrm{min}^{-1}$. Commercial $\alpha-, \gamma-, \delta$-tocopherols were used for calibrations. Total tocopherols content is a combination of $\alpha-, \gamma$-, $\delta$-tocopherols.

\subsection{Ascorbic Acid}

Sufficient plant samples for ascorbic acid analysis were available only for amaranth treatments. The determination of total ascorbic acid of frozen sample was carried out as described in our previous work by Hanson et al. [25] on the basis of coupling 2,4-dinitrophenylhydrazine (DNPH) with the ketonic groups of dehydroascorbic acid through the oxidation of ascorbic acid by 2,6-dichlorophenolindophenol (DCPIP) to give a yellow-orange color in acidic conditions [26]. 


\subsection{Antioxidant Activity}

Frozen samples (20 g each bag) were mixed with $80 \mathrm{ml}$ of methanol in water $(4: 1, \mathrm{v} / \mathrm{v})$. The methanol extracts were measured for antioxidant activity with ABTS 2,2'-azino-bis(3-ethylbenzthiazoline-6-sulphonic acid). The capacity of different components to scavenge the ABTS radical cation was compared with that of trolox in a dose-response curve. The antioxidant activity was expressed as $\mu$ mole trolox equivalent ( $\mu \mathrm{mol}$ TE). The detailed methodology was described in our previous work by Yang et al. [27].

\subsection{Statistical Analysis}

The data were subjected to analysis of variance (ANOVA) using the SAS General Linear Model procedure (SAS Institute, Cary, NC, USA). The entry $(\mathrm{E}) \times$ water $(\mathrm{W})$ interaction mean square tested the effect of the water treatments on the plant response and nutritional values of the different entries. The entries within each crop group were compared. The effect of the water treatment on the entries of the different crop groups $(E \times W)$ was assessed.

\section{Results and Discussion}

The effects of entry, water treatment, and entry $\mathrm{x}$ water interaction were tested for plant response and nutritional measurements. Plant measurements included leaf, root and stem weights, and root and stem heights. Nutritional measurements included antioxidant vitamins (carotenoids, tocopherols, ascorbate), antioxidant activity and minerals of edible portion (EP). The p values of the statistical results are presented in Table 3.

\subsection{Analysis of Variance}

Highly significant differences $(\mathrm{p}<0.01)$ were found in the effects of entry $(\mathrm{E})$ and water $(\mathrm{W})$ treatment for plant weight, plant height and edible yield. The effect of water treatments on the entry $(E \times W)$ was significant for stem and leaf weight.

For nutritional values, the results for the content (based on $100 \mathrm{~g} \mathrm{EP}$ ) and yield (based on actual plant EP) showed different patterns (Table 3). All the nutrient yield results showed significant effects of entry and water. When the content was analysed, no significant difference was observed in water effect for most of the nutrients tested including $\alpha$ - and $\beta$-carotenes, $\alpha$ - and total tocopherols, iron and zinc.

\subsection{Plant Measurements}

The plant weight and height measurements showed that the water-deficient treatment limited root, stem and leaf growth (Table 4). Water-deficient treatment seriously affected plant growth by reducing total dry weight biomass between $10 \%$ - $60 \%$ of total plant dry weight. Among the six entries, A2 lost the most amount of total fresh weight (71.6 g per plant) followed by N1 and K1. Root growth and elongation is a known plant response to water deficit for plant health. The water-deficit condition was severe and the roots systems of the six entries were not able to grow and elongate in response to the drought and maintain plant health. Among the crops, Ethiopian kale had lower root weight and shorter root length than amaranth and nightshade.

The early plant response to water-deficit is to inhibit cell expansion, which results in decreased leaf area to reduce transpiration. Continued water stress causes leaf senescence and abscission. This response is reflected in the reduced leaf area of the crop entries and a decrease in photosynthetic activity. However, specific leaf area, which accounts for total leaf dry weight, measures the crop's leaf expansion against nutrient conservation [28]. In general, drought tolerant plants tend to have lower specific leaf area values than drought vulnerable plants [18]. The differences among crop groups suggest that the Ethiopian kale group was more susceptible to drought stress than amaranth or African nightshade. Moreover, N1 has a higher leaf water content compared to N2. This will give N2 a competitive advantage under drought conditions as it has lower leaf water content even under controlled conditions.

Root elongation and growth is another plant response to water deficit, which in this experiment did not have a significant effect [29]. Under drought conditions, as the surface soil dries up, the roots should extend to deeper moist soils. A deeper root system will allow plants to extract more available water from the soil [30]. The rootto-shoot ratio should be higher in water-stressed plants as growth is concentrated in roots rather than aboveground biomass [31]. However, the plants in this experiment did not show this response. The root-to-shoot ratio 
Table 3. p values for mean squares from the analysis of variance of plant measurements and nutritional measurements of six African indigenous vegetable entries subjected to water-deficient and water-sufficient treatment.

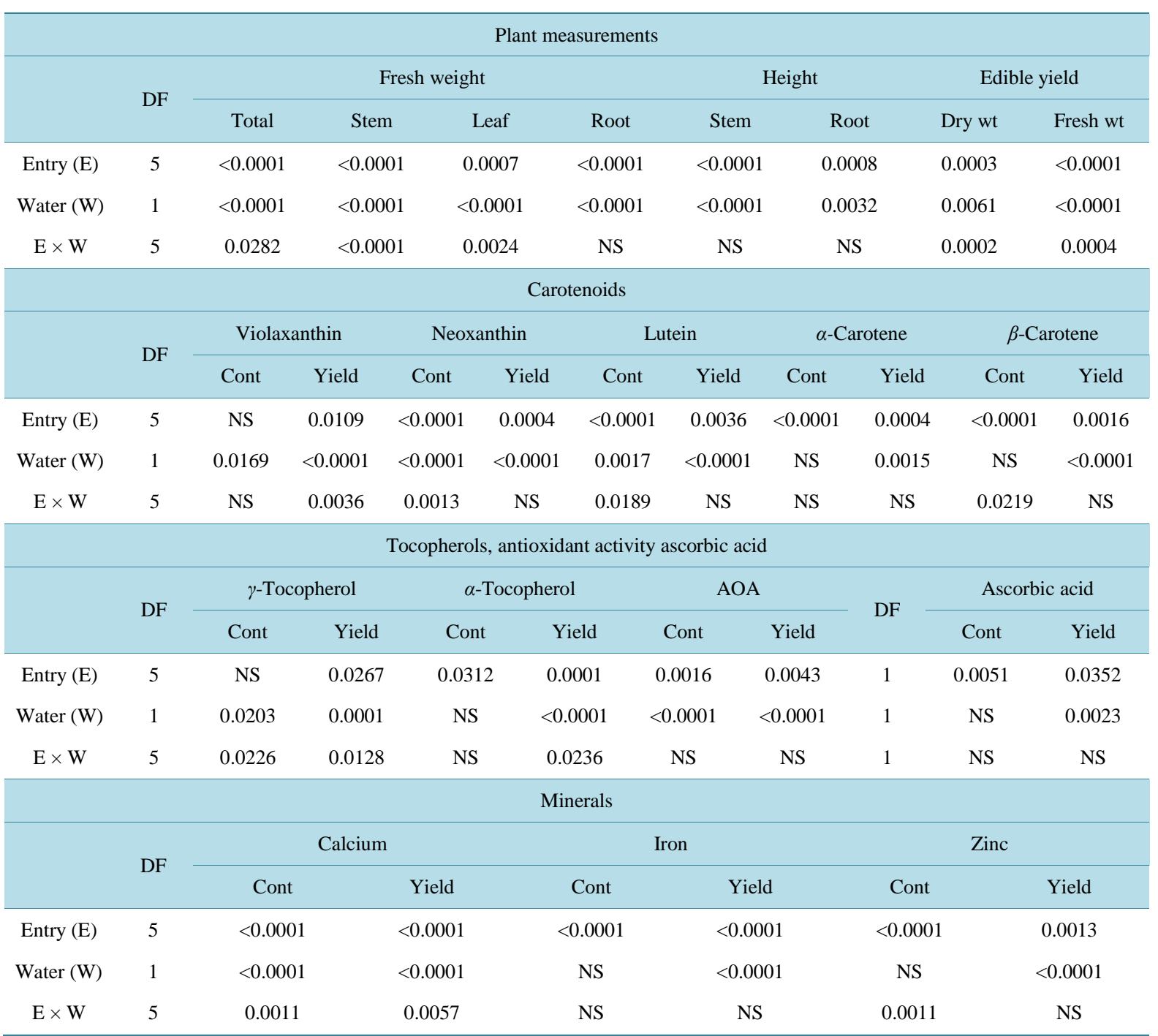

NS, p > 0.05; Cont, nutrient content; Yield, nutrient yield; AOA, antioxidant activity.

Table 4. Plant fresh weight measurements (g per plant) of six African indigenous vegetable entries subjected to water-sufficient (WS) and water-deficient (WD) treatments.

\begin{tabular}{|c|c|c|c|c|c|c|c|c|c|c|}
\hline \multirow{2}{*}{ Entry } & \multicolumn{2}{|c|}{ Total } & \multicolumn{2}{|c|}{ Leaf } & \multicolumn{2}{|c|}{ Stem } & \multicolumn{2}{|c|}{ Root } & \multicolumn{2}{|c|}{ Root: Shoot } \\
\hline & WS & WD & WS & WD & WS & WD & WS & WD & WS & WD \\
\hline A1 & 79.2 & 54.4 & 34.6 & 29.0 & 23.7 & 15.5 & 20.9 & 10.0 & 0.332 & 0.223 \\
\hline A2 & 127.8 & 56.2 & 50.6 & 24.1 & 46.4 & 20.7 & 30.8 & 11.5 & 0.308 & 0.261 \\
\hline K1 & 66.5 & 21.6 & 48.6 & 16.0 & 10.3 & 4.0 & 7.6 & 1.6 & 0.132 & 0.083 \\
\hline K2 & 64.6 & 24.3 & 47.1 & 19.1 & 8.0 & 3.0 & 9.5 & 2.3 & 0.172 & 0.103 \\
\hline N1 & 98.4 & 49.0 & 42.9 & 29.0 & 26.7 & 11.1 & 28.8 & 8.9 & 0.428 & 0.230 \\
\hline N2 & 68.3 & 40.0 & 21.5 & 16.3 & 33.2 & 15.1 & 13.6 & 8.7 & 0.246 & 0.283 \\
\hline $\operatorname{HSD}_{(0.05)}$ & \multicolumn{2}{|c|}{34.7} & \multicolumn{2}{|c|}{19.4} & \multicolumn{2}{|c|}{8.0} & \multicolumn{2}{|c|}{16.1} & \multicolumn{2}{|c|}{0.185} \\
\hline
\end{tabular}

HSD, honestly significant difference. 
only showed a significant difference for African nightshade. An explanation is that the water stress was initiated once the plants were established and did not affect the plants early in the critical root growth stages. Another reason may be due to the potted experiment as plants were not planted in field conditions, the limited depth of the pot could have easily dried up the soil, not allowing roots to find and extend to deeper moist soil. Overall, the fresh stem and leaf weights are decreased under water-deficiency for all crop groups. The total dry weight suggests that the amaranth group had the highest dry yield. Furthermore, early flowering is a common plant response to water stress [32]. Early flowering occurred in the amaranth and African nightshade groups under water-deficit, which may have reduced vegetative growth [33].

\subsection{Nutritional Values}

The nutritional content and nutritional yield (nutrient content $\times$ fresh edible yield) (Tables 5-8) of the vegetables showed different effects in the water-deficient treatment compared with the water-sufficient treatment. The water-deficient condition limited the plant stem, leaf and root growth leading to lower biomass and edible yield, and thus implicated in a lower nutritional yield. However, the accumulation of the phytonutrients including $\alpha$-carotene, $\beta$-carotene, $\alpha$-tocopherol, ascorbic acid, iron and zinc per 100 gram of edible parts was not significantly affected by the water-deficient treatment (Tables 5-8). Overall, the nutritional values in the yield results demonstrated a decreasing trend in the water-deficient treatment, which is consistent to the decrease in fresh edible weight. In the content results, apart from ascorbic acid and tocopherols, most values show an increasing trend. It is worth noting that the selection of vegetables based on either nutrient content or nutrient yield may result in different choices due to the trends of the content and yield results shown in this study.

The nutritional values of amaranth, African nightshade and Ethiopian kale were affected by water deficits on

Table 5. Carotenoid content (mg per $100 \mathrm{~g} \mathrm{EP}$ ) and yield (mg per plant EP) of six African indigenous vegetable entries subjected to water-sufficient (WS) and water-deficient (WD) treatments.

\begin{tabular}{|c|c|c|c|c|c|c|c|c|c|c|c|c|}
\hline \multirow{3}{*}{ Entry } & \multicolumn{4}{|c|}{ Violaxanthin } & \multicolumn{4}{|c|}{ Neoxanthin } & \multicolumn{4}{|c|}{ Lutein } \\
\hline & \multicolumn{2}{|c|}{ Content } & \multicolumn{2}{|c|}{ Yield } & \multicolumn{2}{|c|}{ Content } & \multicolumn{2}{|c|}{ Yield } & \multicolumn{2}{|c|}{ Content } & \multicolumn{2}{|c|}{ Yield } \\
\hline & WS & WD & WS & WD & WS & WD & WS & WD & WS & WD & WS & WD \\
\hline A1 & 2.03 & 2.29 & 1.00 & 0.64 & 1.80 & 1.54 & 0.91 & 0.43 & 5.15 & 4.68 & 2.57 & 1.30 \\
\hline A2 & 1.42 & 2.27 & 0.97 & 0.79 & 1.75 & 1.98 & 1.18 & 0.69 & 4.33 & 4.88 & 2.90 & 1.69 \\
\hline K1 & 1.92 & 1.81 & 1.58 & 0.45 & 1.67 & 2.49 & 1.36 & 0.69 & 3.82 & 4.08 & 3.17 & 1.10 \\
\hline $\mathrm{K} 2$ & 1.81 & 1.59 & 1.63 & 0.43 & 1.52 & 2.00 & 1.36 & 0.49 & 3.04 & 3.96 & 2.74 & 1.04 \\
\hline N1 & 1.74 & 2.53 & 1.17 & 0.94 & 2.16 & 3.44 & 1.43 & 1.29 & 5.02 & 7.59 & 3.30 & 2.88 \\
\hline N2 & 2.12 & 2.59 & 0.55 & 0.39 & 2.59 & 3.35 & 0.71 & 0.50 & 6.27 & 7.20 & 1.74 & 1.07 \\
\hline \multirow[t]{2}{*}{$\operatorname{HSD}_{(0.05)}$} & \multicolumn{2}{|c|}{1.16} & \multicolumn{2}{|c|}{0.82} & \multicolumn{2}{|c|}{0.82} & \multicolumn{2}{|c|}{0.77} & \multicolumn{2}{|c|}{1.99} & \multicolumn{2}{|c|}{1.88} \\
\hline & \multicolumn{4}{|c|}{$\alpha$-Carotene } & \multicolumn{4}{|c|}{$\beta$-Carotene } & \multicolumn{4}{|c|}{ Total carotenoids } \\
\hline \multirow[t]{2}{*}{ Entry } & \multicolumn{2}{|c|}{ Content } & \multicolumn{2}{|c|}{ Yield } & \multicolumn{2}{|c|}{ Content } & \multicolumn{2}{|c|}{ Yield } & \multicolumn{2}{|c|}{ Content } & \multicolumn{2}{|c|}{ Yield } \\
\hline & WS & WD & WS & WD & WS & WD & WS & WD & WS & WD & WS & WD \\
\hline A1 & 0.20 & 0.20 & 0.10 & 0.05 & 4.31 & 3.35 & 2.18 & 0.93 & 13.49 & 12.05 & 6.75 & 3.35 \\
\hline $\mathrm{A} 2$ & 0.25 & 0.18 & 0.18 & 0.06 & 4.47 & 4.82 & 3.03 & 1.67 & 12.23 & 14.12 & 8.24 & 4.89 \\
\hline K1 & 0.07 & 0.05 & 0.05 & 0.01 & 2.64 & 3.04 & 2.16 & 0.78 & 10.12 & 11.47 & 8.31 & 3.03 \\
\hline $\mathrm{K} 2$ & 0.06 & 0.06 & 0.06 & 0.01 & 2.50 & 2.51 & 2.26 & 0.67 & 8.93 & 10.12 & 8.04 & 2.65 \\
\hline $\mathrm{N} 1$ & 0.21 & 0.28 & 0.15 & 0.11 & 3.50 & 5.21 & 2.30 & 1.98 & 12.62 & 19.03 & 8.35 & 7.19 \\
\hline N2 & 0.16 & 0.21 & 0.05 & 0.03 & 4.26 & 5.14 & 1.20 & 0.75 & 15.39 & 18.47 & 4.24 & 2.73 \\
\hline $\operatorname{HSD}_{(0.05)}$ & \multicolumn{2}{|c|}{0.14} & \multicolumn{2}{|c|}{0.12} & \multicolumn{2}{|c|}{1.78} & \multicolumn{2}{|c|}{1.58} & \multicolumn{2}{|c|}{5.15} & \multicolumn{2}{|c|}{4.96} \\
\hline
\end{tabular}

HSD, honestly significant difference; EP, edible portion. 
Table 6. Tocopherol content (mg per $100 \mathrm{~g}$ EP) and yield (mg per plant EP) of six African indigenous vegetable entries subjected to water-sufficient (WS) and water-deficient (WD) treatments.

\begin{tabular}{|c|c|c|c|c|c|c|c|c|c|c|c|c|}
\hline \multirow{3}{*}{ Entry } & \multicolumn{4}{|c|}{$\gamma$-Tocopherol } & \multicolumn{4}{|c|}{$\alpha$-Tocopherol } & \multicolumn{4}{|c|}{ Total tocopherols } \\
\hline & \multicolumn{2}{|c|}{ Content } & \multicolumn{2}{|c|}{ Yield } & \multicolumn{2}{|c|}{ Content } & \multicolumn{2}{|c|}{ Yield } & \multicolumn{2}{|c|}{ Content } & \multicolumn{2}{|c|}{ Yield } \\
\hline & WS & WD & WS & WD & WS & WD & WS & WD & WS & WD & WS & WD \\
\hline A1 & 0.05 & 0.06 & 0.03 & 0.02 & 3.02 & 3.65 & 1.54 & 1.03 & 3.07 & 3.71 & 1.57 & 1.05 \\
\hline A2 & 0.24 & 0.02 & 0.14 & 0.01 & 2.32 & 0.74 & 1.48 & 0.26 & 2.56 & 0.76 & 1.61 & 0.27 \\
\hline K1 & 0.05 & 0.05 & 0.04 & 0.02 & 3.00 & 3.78 & 2.44 & 1.00 & 3.04 & 3.83 & 2.47 & 1.01 \\
\hline K2 & 0.04 & 0.05 & 0.04 & 0.02 & 2.73 & 3.86 & 2.43 & 0.97 & 2.77 & 3.91 & 2.47 & 0.98 \\
\hline $\mathrm{N} 1$ & 0.09 & 0.02 & 0.06 & 0.01 & 4.79 & 1.96 & 3.01 & 0.85 & 4.88 & 1.98 & 3.07 & 0.86 \\
\hline $\mathrm{N} 2$ & 0.10 & 0.06 & 0.03 & 0.01 & 4.85 & 3.87 & 1.08 & 0.51 & 4.95 & 3.93 & 1.10 & 0.52 \\
\hline $\operatorname{HSD}_{(0.05)}$ & \multicolumn{2}{|c|}{0.18} & \multicolumn{2}{|c|}{0.08} & \multicolumn{2}{|c|}{3.84} & \multicolumn{2}{|c|}{1.26} & \multicolumn{2}{|c|}{3.92} & \multicolumn{2}{|c|}{1.29} \\
\hline
\end{tabular}

HSD, honestly significant difference; EP, edible portion.

Table 7. Antioxidant activity and ascorbic acid measurements of six African indigenous vegetable entries subjected to water-sufficient (WS) and water-deficient (WD) treatments.

\begin{tabular}{|c|c|c|c|c|c|c|c|c|c|c|c|c|}
\hline \multirow{3}{*}{ Entry } & \multicolumn{4}{|c|}{ Edible portion (g) } & \multicolumn{4}{|c|}{$\begin{array}{c}\text { Antioxidant activity } \\
(\mu \mathrm{mol} \text { trolox equivalent })\end{array}$} & \multicolumn{4}{|c|}{ Ascorbic acid (mg) } \\
\hline & \multicolumn{2}{|c|}{ Fresh weight } & \multicolumn{2}{|c|}{ Dry weight } & \multicolumn{2}{|c|}{ Content } & \multicolumn{2}{|c|}{ Yield } & \multicolumn{2}{|c|}{ Content } & \multicolumn{2}{|c|}{ Yield } \\
\hline & WS & WD & WS & WD & WS & WD & WS & WD & WS & WD & WS & WD \\
\hline A1 & 51.0 & 28.1 & 14.4 & 12.8 & 875 & 860 & 446 & 240 & 69 & 67 & 36 & 19 \\
\hline A2 & 64.9 & 34.6 & 13.3 & 12.2 & 873 & 976 & 561 & 337 & 88 & 75 & 57 & 26 \\
\hline K1 & 81.0 & 27.0 & 11.5 & 12.6 & 606 & 800 & 499 & 202 & - & - & - & - \\
\hline K2 & 90.5 & 26.1 & 10.6 & 12.5 & 686 & 1027 & 623 & 252 & - & - & - & - \\
\hline N1 & 64.5 & 38.2 & 10.0 & 12.5 & 744 & 1048 & 485 & 400 & - & - & - & - \\
\hline $\mathrm{N} 2$ & 25.7 & 14.4 & 11.5 & 13.7 & 937 & 1237 & 249 & 177 & - & - & - & - \\
\hline $\operatorname{HSD}_{(0.05)}$ & \multicolumn{2}{|c|}{28.6} & \multicolumn{2}{|c|}{2.4} & \multicolumn{2}{|c|}{388} & \multicolumn{2}{|c|}{311} & \multicolumn{2}{|c|}{17} & \multicolumn{2}{|c|}{25} \\
\hline
\end{tabular}

HSD, honestly significant difference; EP, edible portion; -, no data.

Table 8. Mineral content (mg per $100 \mathrm{~g}$ EP) and yield ((mg per plant EP) of six African indigenous vegetable entries subjected to water-sufficient (WS) and water-deficient (WD) treatments.

\begin{tabular}{|c|c|c|c|c|c|c|c|c|c|c|c|c|}
\hline \multirow{3}{*}{ Entry } & \multicolumn{4}{|c|}{ Calcium } & \multicolumn{4}{|c|}{ Iron } & \multicolumn{4}{|c|}{ Zinc } \\
\hline & \multicolumn{2}{|c|}{ Content } & \multicolumn{2}{|c|}{ Yield } & \multicolumn{2}{|c|}{ Content } & \multicolumn{2}{|c|}{ Yield } & \multicolumn{2}{|c|}{ Content } & \multicolumn{2}{|c|}{ Yield } \\
\hline & WS & WD & WS & WD & WS & WD & WS & WD & WS & WD & WS & WD \\
\hline A1 & 223 & 228 & 113 & 64 & 3.35 & 3.16 & 1.76 & 0.87 & 0.67 & 0.56 & 0.35 & 0.16 \\
\hline A2 & 224 & 229 & 147 & 79 & 2.85 & 2.81 & 1.84 & 0.93 & 0.85 & 0.72 & 0.56 & 0.24 \\
\hline K1 & 185 & 200 & 150 & 54 & 1.05 & 1.00 & 0.86 & 0.27 & 0.58 & 0.64 & 0.48 & 0.17 \\
\hline K2 & 186 & 202 & 169 & 51 & 1.13 & 1.34 & 1.02 & 0.33 & 0.54 & 0.73 & 0.49 & 0.18 \\
\hline N1 & 230 & 272 & 149 & 104 & 2.58 & 3.32 & 1.64 & 1.27 & 0.56 & 0.70 & 0.37 & 0.27 \\
\hline N2 & 155 & 241 & 41 & 35 & 4.13 & 5.09 & 1.08 & 0.71 & 0.90 & 0.81 & 0.24 & 0.12 \\
\hline $\operatorname{HSD}_{(0.05)}$ & \multicolumn{2}{|c|}{48} & \multicolumn{2}{|c|}{69} & \multicolumn{2}{|c|}{1.58} & \multicolumn{2}{|c|}{0.95} & \multicolumn{2}{|c|}{0.21} & \multicolumn{2}{|c|}{0.24} \\
\hline
\end{tabular}

HSD, honestly significant difference; EP, edible portion. 
two levels. First, at the content level, where all the values were calculated based on 100 g quantities, most values, with the exception of ascorbic acid, showed an increase in the water-deficient treatment compared to the watersufficient treatment for all the entries. Under drought stress conditions, antioxidants and specific osmolytes accumulate to maintain cell turgor and stabilize cell proteins [34]. AOA values increased in water-deficit conditions in the content results. Carotenoids and tocopherols are fat-soluble compounds while ascorbic acid is watersoluble. Therefore, ascorbic acid values may have decreased at the content level due to the loss of water, its main transport mechanism [35]. Transpiration and other processes of plant water loss during drought may have increased the content of micronutrients and minerals in the plants [36].

Second, once the content values were recalculated to account for the actual fresh edible weight of each entry, the nutritional values reflected a decrease in overall nutritional yield under water stress. The slight content increases are masked by an overall decline in fresh edible weight in water-deficient entries. Nutritional value is strongly related to crop yield. Although at the content level, the entries showed higher values in drought-stressed conditions, its overall yield is compromised. The actual nutritional yield values have a greater implication for crop selection and food security than their content values.

From the experimental results, A2 (A. hypochondriacus) can be considered to be more drought tolerant than A1 (A. cruentus) and retained higher nutritional values. N2 (S. villosum), however, generally showed higher nutritional values in the water-sufficient treatment, but had higher losses in the water-deficient treatment than N1 (S. scabrum). Therefore, N1 (S. scabrum) is the more nutritious choice for African nightshade. K1 and K2 (B. carinata) had the least drought tolerant among the six vegetables regarding the most severe loss of edible portions and lower nutrient contents and yields. Indigenous vegetables are considered to have stronger water stress adaptation mechanisms than common, commercially available vegetables [14]. Further research could include a comparison of the nutritional yield in indigenous and non-indigenous vegetable food crops under water-deficient conditions.

\subsection{Limitations and Future Study}

The crop yield was affected by many uncontrollable variables in the glasshouse. Both Ethiopian kale varieties were attacked at seedling stage by whiteflies and diamondback moth larvae. Pest problems early in the growth stage of the crop reflect a reduced yield at maturity. African nightshade was subjected to spider mite infestation approximately 10 days before harvest. The consequences were reduced growth and leaf abscission, which severely reduced the yield.

The experiment was meant as a pilot study to a larger scale, open-field experiment in semi-arid Africa. The glasshouse conditions, such as temperature, daylight period and relative humidity of this pilot study did not fully reflect the situation in Africa. Water scheduling instead of water quantity was used in this experiment to imitate practices of home gardeners or smallholder farmers. Growers will only water their plants when there is water available. It may take many days before water can be collected and used. Although this experiment demonstrated that certain leafy indigenous vegetables could be grown in water-deficient conditions, it is crucial to water the plants at the seedling stage until they are mature enough to withstand extreme water stresses.

Water deficit limits edible biomass production in the leafy African vegetables of the study. The edible fresh weight decline in water-deficient varieties is directly related to the decrease in their nutritional values. At the content level, the values showed an increase in water-deficient varieties. Amaranth and African nightshade have shown promising results in drought conditions, Ethiopian Kale, however showed poor yields. Among each crop groups, A2 (A. hypochondriacus) and N1 (S. scabrum) are recommended as drought tolerant indigenous vegetables for community adaptation programs.

\section{Acknowledgements}

We acknowledge the collaboration between McGill University and AVRDC-The World Vegetable Center for the work on this study. We are grateful for Dr. Bernard Pelletier's statistical support and the assistance of Jane $\mathrm{Wu}$, the AVRDC Nutrition Unit, and Taiwan university students in the laboratory.

\section{References}

[1] Zimmer, D. and Renault, D. (2003) Virtual Water in Food Production and Global Trade: Review of Methodological 
Issues and Preliminary Results. Proceedings of the International Expert Meeting on Virtual Water Trade, Value of Water-Research Rapport Series, No. 12, 93-109.

[2] ACB (2009) Patents, Climate Change and African Agriculture: Dire Predictions. ACB Briefing Paper No. 10, African Centre for Biosafety, Melville, 12.

[3] Postel, S.L. (1998) Water for Food Production: Will There Be Enough in 2025? BioScience, 48, 629-637. http://dx.doi.org/10.2307/1313422

[4] Unmüßig, B. and Cramer, S. (2008) Climate Change in Africa. GIGA Focus Afrika, No. 2, 1-8.

[5] Osman-Elasha, B. (2009) Climate Change Impacts, Adaptation and Links to Sustainable Development in Africa. Unasylva, 60, 12-16.

[6] Kuhnlein, H.V. and Receveur, O. (1996) Dietary Change and Traditional Food Systems of Indigenous Peoples. Annual Review of Nutrition, 16, 417-442. http://dx.doi.org/10.1146/annurev.nu.16.070196.002221

[7] Okeno, J.A., Chebet, D.K. and Mathenge, P.W. (2002) Status of Indigenous Vegetable Utilization in Kenya. Acta Horticulturae 621, 95-100.

[8] Jansen Van Rensburg, W.S., Venter, S.L., Netshiluvhi, T.R., Van Den Heever, E., Vorster, H.J. and De Ronde, J.A. (2004) Role of Indigenous Leafy Vegetables in Combating Hunger and Malnutrition. South African Journal of Botany, 70, 52-59.

[9] Weinberger, K. and Swai, I. (2006) Consumption of Traditional Vegetables in Central and Northeastern Tanzania. Ecology of Food and Nutrition, 45, 87-103. http://dx.doi.org/10.1080/03670240500530626

[10] Grubben, G.J.H. and Denton, O.A. (2004) Plant Resources of Tropical Africa 2. Vegetables. PROTA Foundation, Wageningen, Netherlands. PROTA Foundation, Wageningen.

[11] Orech, F.O., Christensen, D.L., Larsen, T., Friis, H., Aagaard-Hansen, J. and Estambale, B.A. (2007) Mineral Content of Traditional Leafy Vegetables from Western Kenya. International Journal of Food Sciences and Nutrition, 58, 595-602. http://dx.doi.org/10.1080/09637480701350288

[12] Yang, R.-Y. and Keding, G.B. (2009) Nutritional Contributions of Important African Indigenous Vegetables. In: Shakleton, C.M., Pasquini, M.W. and Drescher, A.W., Eds., African Indigenous Vegetables in Urban Agriculture, Earthscan, London, 105-143.

[13] Jansen van Rensburg, W.S., Van Averbeke, W., Slabbert, R., Faber, M., Van Jaarsveld, P., Van Heerden, I., Wenhold, F. and Oelofse, A. (2007) African Leafy Vegetables in South Africa. Water SA, 33, 317-326.

[14] Slabbert, R. and Van den Heever, E. (2006) Selection of Traditional Crops for Improved Drought Tolerance in Leafy Amaranth: Moving towards Sustainable Food Supply. I International Conference on Indigenous Vegetables and Legumes. Prospectus for Fighting Poverty, Hunger and Malnutrition 752, 281-286.

[15] Liu, F. and Stützel, H. (2004) Biomass Partitioning, Specific Leaf Area, and Water Use Efficiency of Vegetable Amaranth (Amaranthus Spp.) in Response to Drought Stress. Scientia Horticulturae, 102, 15-27. http://dx.doi.org/10.1016/j.scienta.2003.11.014

[16] Masinde, P.W., Stützel, H., Agong, S.G. and Fricke, A. (2006) Plant Growth, Water Relations and Transpiration of Two Species of African Nightshade (Solanum villosum Mill. ssp. Miniatum (Bernh. Ex Willd.) Edmonds and S. sarrachoides Sendtn.) under Water-Limited Conditions. Scientia Horticulturae, 110, 7-15. http://dx.doi.org/10.1016/j.scienta.2006.06.003

[17] Kramer, P.J. (1983) Water Relations of Plants. Academic Press, New York.

[18] Taiz, L. and Zeiger, E. (2002) Plant Physiology. Sinauer Associates, Inc., Sunderland.

[19] Weinberger, K. and Msuya, J. (2004) Indigenous Vegetables in Tanzania: Significance and Prospects. Technical Bulletin, 31, 1-600.

[20] AOAC (1990) Methods of Analysis. 15th Edition, Association of Official Analytical Chemists, Arlington.

[21] Mínguez-Mosquera, M.I., Gandul-Rojas, B., Montaño-Asquerino, A. and Garrido-Fernández, J. (1991) Dertermination of Chlorophylls and Carotenoids by High-Performance Liquid Chromatography during Olive Lactic Fermentation. Journal of Chromatography A, 585, 259-266. http://dx.doi.org/10.1016/0021-9673(91)85086-U

[22] Larsen, E. and Christensen, L.P. (2005) Simple Saponification Method for the Quantitative Determination of Carotenoids in Green Vegetables. Journal of Agricultural and Food Chemistry, 53, 6598-6602. http://dx.doi.org/10.1021/jf050622+

[23] Hanson, P., Yang, R., Chang, L., Ledesma, L. and Ledesma, D. (2009) Contents of Carotenoids, Ascorbic Acid, Minerals and Total Glucosinolates in Leafy Brassica Pakchoi (Brassica rapa L. chinensis) as Affected by Season and Variety. Journal of the Science of Food and Agriculture, 89, 906-914. http://dx.doi.org/10.1002/jsfa.3533

[24] Osuna-García, J.A., Wall, M.M. and Waddell, C.A. (1998) Endogenous Levels of Tocopherols and Ascorbic Acid 
during Fruit Ripening of New Mexican-Type Chile (Capsicum annuum L.) Cultivars. Journal of Agricultural and Food Chemistry, 46, 5093-5096. http://dx.doi.org/10.1021/jf980588h

[25] Hanson, P.M., Yang, R., Wu, J., Chen, J., Ledesma, D., Tsou, S.C.S. and Lee, T.-C. (2004) Variation for Antioxidant Activity and Antioxidants in Tomato. Journal of the American Society for Horticultural Science, 129, 704-711.

[26] Pelletier, O. (1985) Vitamin C, (L-Ascorbic and Dehydro-L-Ascorbic Acids). In: Augustin, J., Klein, B., Becker, D. and Venugopal, P., Eds., Methods of Vitamin Assay, 4th Edition, Wiley, New York, 303-347.

[27] Yang, R.Y., Tsou, S., Lee, T.C., Wu, W.J., Hanson, P.M., Kuo, G., Engle, L.M. and Lai, P.Y. (2006) Distribution of 127 Edible Plant Species for Antioxidant Activities by Two Assays. Journal of the Science of Food and Agriculture, 86, 2395-2403. http://dx.doi.org/10.1002/jsfa.2630

[28] Garnier, E., Shipley, B., Roumet, C. and Laurent, G. (2001) A Standardized Protocol for the Determination of Specific Leaf Area and Leaf Dry Matter Content. Functional Ecology, 15, 688-695. http://dx.doi.org/10.1046/j.0269-8463.2001.00563.x

[29] Sharp, R.E., Poroyko, V., Hejlek, L.G., Spollen, W.G., Springer, G.K., Bohnert, H.J. and Nguyen, H.T. (2004) Root Growth Maintenance during Water Deficits: Physiology to Functional Genomics. Journal of Experimental Botany, 55, 2343-2351. http://dx.doi.org/10.1093/jxb/erh276

[30] Martin, B. and Thorstenson, Y.R. (1988) Stable Carbon Isotope Composition ( $\delta 13 \mathrm{C})$, Water Use Efficiency, and Biomass Productivity of Lycopersicon esculentum, Lycopersicon pennellii, and the F1 Hybrid. Plant Physiology, 88, 213217. http://dx.doi.org/10.1104/pp.88.1.213

[31] Malik, R.S., Dhankar, J.S. and Turner, N.C. (1979) Influence of Soil Water Deficits on Root Growth of Cotton Seedlings. Plant and Soil, 53, 109-115. http://dx.doi.org/10.1007/BF02181885

[32] Turner, N.C. (1986) Adaptation to Water Deficits: A Changing Perspective. Australian Journal of Plant Physiology, 13, 175-190.

[33] Steeves, T.A. and Sussex, I.M. (1989) Patterns in Plant Development. Cambridge University Press, New York. http://dx.doi.org/10.1017/CBO9780511626227

[34] Seki, M., Umezawa, T., Urano, K. and Shinozaki, K. (2007) Regulatory Metabolic Networks in Drought Stress Responses. Current Opinion in Plant Biology, 10, 296-302. http://dx.doi.org/10.1016/j.pbi.2007.04.014

[35] Rose, R.C. (1988) Transport of Ascorbic Acid and Other Water-Soluble Vitamins. Biochimica et Biophysica Acta, 947, 335-366.

[36] Hu, Y.C. and Schmidhalter, U. (2005) Drought and Salinity: A Comparison of Their Effects on Mineral Nutrition of Plants. Journal of Plant Nutrition and Soil Science, 168, 541-549. http://dx.doi.org/10.1002/jpln.200420516 